\title{
AVALIAÇÃO DA QUALIDADE BIOLÓGICA, MICROBIOLÓGICA E POR METAIS PESADOS DAS ÁGUAS DOS PRINCIPAIS RESERVATÓRIOS DO RIO GRANDE DO NORTE
}

\author{
J. A. S. GRILO JUNIOR ${ }^{1}$, R. F. FIDELIS ${ }^{2}$, M.B. VALE ${ }^{3}$, C. C. M. BRAGA ${ }^{4}$, J. K. S. OLIVEIRA ${ }^{5}$ \\ Instituto Federal de Educação, Ciência e Tecnologia do Rio Grande de Norte \\ jose.junior@ifrn.edu.br ${ }^{1}$
}

Artigo submetido em 22/01/2016 e aceito em 09/08/2019

DOI: $10.15628 /$ holos.2019.4020

\begin{abstract}
RESUMO
O presente trabalho tem por objetivo avaliar a qualidade das águas dos principais reservatórios de abastecimento público no estado do Rio Grande do Norte. As coletas foram realizadas em pontos pré-estabelecidos nos açude em estudo em cinco semanas consecutivas. Foram analisados os aspectos biológicos, microbiológicos e por metais pesados dos principais reservatórios de água de Rio Grande do Norte (RN). Condições de balneabilidade dos reservatórios. O estudo identificou como sendo de boa qualidade para maioria dos açudes estudados e de ótima qualidade somente para Boqueirão-Parelhas. Verificou-se que a quantificação de densidade de Cianobactérias nos corpos d'água de Lucrécia, Armando Ribeiro, de Pau dos Ferros, Passagem das Traíras e
\end{abstract}

Gargalheiras estavam superiores ao permitido pela legislação indicando processo de eutrofização, podendo causar problema a saúde humana e aos animais. Em relação aos níveis de metais pesados, todos apresentaram algum metal acima do limite permitido, porém todos apresentaram valor acima do limite para o cádmio, a Barragem de Santa Cruz apresentou menor quantidade de matais. A avaliação da Balneabilidade constatou que as barragens de Pau dos Ferros e Santa Cruz foram classificadas como impróprio para a atividade de recreação de contato primário, enquanto que os demais pontos foram enquadrados como excelente. A maioria das águas dos reservatórios estudados está inadequada para dessedentação de animais.

PALAVRAS-CHAVE: Balneabilidade, qualidade da água, reservatórios hídricos.

\section{VALUATION OF BIOLOGICAL QUALITY, MICROBIOLOGICAL AND FOR HEAVY METALS IN THE WATERS OF THE MAIN RESERVOIRS OF RIO GRANDE DO NORTE}

\begin{abstract}
This study aims to assess the water quality of the main public water supply reservoirs in the state of Rio Grande do Norte. Samples were taken at set points in the reservoir under study in five consecutive weeks. Biological, microbiological and heavy metals major Rio Grande do Norte water reservoirs (RN) were analyzed. bathing conditions of the reservoirs. The study identified as being of good quality for most of the studied ponds and great quality only Boqueirao-Parelhas. It was found that the quantification of cyanobacteria density in water bodies of Lucretia, Armando Ribeiro, Pau dos Ferros,
\end{abstract}

Crossing Traíras and Gargalheiras were higher than allowed by law indicating process of eutrophication, may cause problem to human health and the animals. For heavy metals levels, all showed some metal above the allowed limit, but all showed value over the limit for cadmium, the dam of Santa Cruz presented fewer matais. The assessment found that bathing dam Pau dos Ferros and Santa Cruz were classified as unfit for primary contact recreation activity, while the other points were classified as excellent. Most of the waters of the reservoirs is unsuitable for watering livestock.

KEYWORDS: balneability, water quality, water reservoirs. 


\section{INTRODUÇÃO}

O constante crescimento demográfico, e a consequente expansão econômica acarretam um aumento da demanda de água, em virtude tanto da ampliação do número de usos atribuídos a ela, como o volume requerido por cada um destes usos. Além do aumento das demandas são também notórios os problemas de deterioração da qualidade das águas em decorrência da poluição (Silva \& Pruski, 2000).

As águas de superfície são as de mais fácil captação e por isso são as mais utilizadas no consumo humano. No entanto, as águas superficiais raramente estão livres de contaminação, mesmo nas bacias com pouca ou nenhuma atividade humana. A ocupação desordenada de uma bacia provoca grandes alterações na qualidade da água, com a poluição gerada pela atividade urbana, em função do esgoto doméstico, industrias e escoamento da água das chuvas, dejetos animais e agrotóxicos da atividade rural (GASPARINI, 2001).

Entender o funcionamento de lagos e reservatórios significa entender o comportamento de suas atividades físicas, químicas e biológicas, bem como, compreender os processos que governam o desenvolvimento dessas atividades, de modo a permitir a avaliação precisa nos parâmetros que determinam os aspectos da qualidade da água dos mesmos (Ribeiro, 2007).

Devido a grandes períodos sem chuvas no Nordeste brasileiro, a construção dos açudes tornou-se uma grande alternativa dos governantes para aumentar a disponibilidade de água na região, porém, pouco se conhece sobre esses corpos hídricos (BARBOSA, 2002).

As águas destes reservatórios estão sujeitas a interferência na sua qualidade devido às condições climatológica, sobretudo por estarem localizados na região do semiárido nordestino, o que pode acarretar na salinização de suas águas. Agravando-se pela interferência do homem, através do lançamento de efluentes industriais e domésticos nos corpos d'águas, aplicação de fertilizantes e pesticidas na agricultura, além das queimadas, destruição das matas ciliares e formação de lixões dentro de zona de preservação dos corpos hídricos.

O monitoramento da qualidade das águas dos reservatórios do estado visa preservar a saúde da população de forma geral, visto que as mesmas são fonte de captação de água para abastecimento das principais cidades do semiárido do Rio Grande do Norte. O monitoramento favorece o planejamento da demanda dos recursos hídricos e do consumo na utilização para lazer, agricultura e indústria, por esse motivo há a necessidade de gerenciamento dos mananciais de abastecimento público de água. No gerenciamento dos reservatórios de água é essencial o monitoramento dos parâmetros microbiológicos e por metais pesados da qualidade de água que, por sua vez, permitam inferir sobre possíveis fontes de poluentes que possam prejudicar o uso a que estes reservatórios são destinados (Lima e Garcia, 2008). Uma vez contaminados, estes mananciais podem oferecer riscos à saúde da população abastecida. Dessa forma, o presente trabalho teve como objetivo avaliar a qualidade da água no que se refere aos padrões biológicos, microbiológicos e por metais pesados dos principais reservatórios do RN. 


\section{MATERIAIS E MÉTODOS}

Os nove reservatórios hídricos estão distribuídos nas regiões do Seridó Potiguar abrangendo os reservatórios de Barragem Passagem das Traíras, Barragem de Boqueirão de Parelhas, Açude de Gargalheiras e Açude Itans. Na região Oeste Potiguar alcançando os seguintes reservatórios hídricos: Barragem Engenheiro Armando Ribeiro Gonçalves, Barragem de Santa Cruz do Apodi, Açude de Bananeiras e Açude de Lucrécia.

Figura 1 - Localização dos reservatórios.

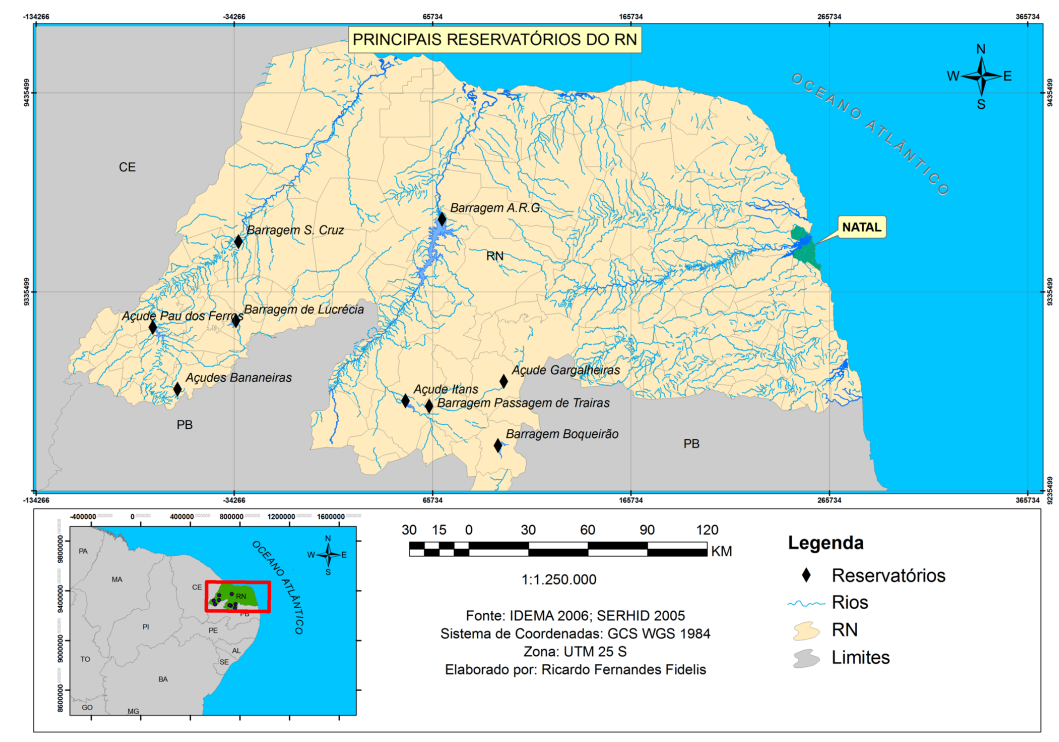

Fonte: Elaborado pelos autores (2013).

A amostragem das águas dos reservatórios foi realizada em um local de maior fluxo de banhistas, foi escolhido um ponto de coleta para cada reservatório no qual foi georreferenciado com GPS (Tabela 1).

Tabela 1 - Descrição e localização dos Pontos de Coleta

\begin{tabular}{|c|c|c|c|}
\hline Ponto & Açude & Município & $\begin{array}{c}\text { Coordenadas } \\
\text { (UTM) }\end{array}$ \\
\hline 1 & Açude Bananeiras & Alexandria & $\begin{array}{r}601390 \\
9289274\end{array}$ \\
\hline 2 & $\begin{array}{l}\text { Barragem de Pau } \\
\text { dos Ferros }\end{array}$ & Pau dos Ferros & $\begin{array}{r}589297 \\
9320400\end{array}$ \\
\hline 3 & $\begin{array}{l}\text { Barragem Santa } \\
\text { Cruz do Apodi }\end{array}$ & Apodi & $\begin{array}{r}632793 \\
9362886\end{array}$ \\
\hline 4 & Açude de Lucrécia & Lucrécia & $\begin{array}{r}631033 \\
9323480\end{array}$ \\
\hline 5 & & Itajá & 735334 \\
\hline
\end{tabular}




\begin{tabular}{|c|c|c|c|}
\hline & $\begin{array}{c}\text { Barragem Armando } \\
\text { Ribeiro Gonçalves }\end{array}$ & & 9373036 \\
\hline 6 & $\begin{array}{l}\text { Barragem } \\
\text { Boqueirão de } \\
\text { Parelhas }\end{array}$ & Parelhas & $\begin{array}{r}762135 \\
9259088\end{array}$ \\
\hline 7 & $\begin{array}{c}\text { Barragem } \\
\text { Passagem da } \\
\text { Traíras }\end{array}$ & Jardim do Seridó & $\begin{array}{r}727715 \\
9279278\end{array}$ \\
\hline 8 & Açude de Itans & Caicó & $\begin{array}{c}715891 \\
928213\end{array}$ \\
\hline 9 & $\begin{array}{c}\text { Açude de } \\
\text { Gargalheiras }\end{array}$ & Acari & $\begin{array}{l}0765529 \\
9291258\end{array}$ \\
\hline
\end{tabular}

As amostragens foram realizadas sempre nos mesmos pontos pré-estabelecidos durante cinco semanas distribuídas no período de 10 de maio a 07 de abril de 2013, sempre aos domingos e geralmente no período da manhã, entre as $9 \mathrm{~h}$ e $12 \mathrm{~h}$, numa profundidade média de 1,0 m para balneabilidade e de $30 \mathrm{~cm}$ para as análises físico-químicas. Para cada amostra foram coletados 100 $\mathrm{mL}$ de água em frascos esterilizados para balneabilidade e (dois) 2 litros para análises físicoquímicas. Nos frascos com destino a contagem de células, foram adicionados $3 \mathrm{~mL}$ de solução lugol, em $300 \mathrm{~mL}$ de amostra. Imediatamente após cada coleta, estas amostras foram conservadas sob refrigeração e transportadas para determinações no Laboratório de Análise de Águas do IFRN Campus Natal-Central.

Os mananciais superficiais foram avaliados através de análises bacteriológicas (coliformes termotolerantes) e físico-químicas, realizadas segundo procedimentos recomendados pela APHAAWWA-WPQCF (APHA et al, 2005).

Na necessidade de métodos mais rápidos para a detecção e quantificação de Coliformes termotolerantes, foi usada técnica de tubos múltiplos, com a inoculação no meio de cultura $A_{1}$.

O Standard methods (US-EPA) for examination of water and wastewater, em sua $21^{\mathrm{a}}$ edição, recomenda este método com meio $A_{1}$ para análises de água de fonte, águas marinhas e águas residuárias tratadas.

Emprega-se um procedimento simplificado, com inoculação direta da amostra do meio $A_{1}$ e incubação a $44,5 \pm 0,2^{\circ} \mathrm{C}$ durante 24 horas. A produção de gases (hidrogênio e dióxido de carbono) e de ácido, a partir da fermentação da lactose do meio $A_{1}$, é prova confirmativa positiva para a presença de bactérias do grupo dos coliformes termotolerantes.

Para as cianobactérias foram realizados somente ensaios quantitativos (contagem de células de cianobactérias (cel/ $\mathrm{mL})$ ). A contagem de células de cianobactérias foi realizada em microscópio binocular, na câmara de Sedgwick - Rafter, com recolo de Whipple acoplado na ocular, seguindo a Norma Técnica CETESB L5 303, (2012).

Quanto aos metais pesados foi utilizado o método espectrofotometria de absorção atômica, segundo a APHA et al. (2005) 
Considerando que a saúde e o bem-estar humano podem ser afetados pelas condições de balneabilidade e de acordo com a Resolução № 274 de 29 de novembro de 2000 do CONAMA, são estabelecidos critérios para a classificação das águas destinadas a balneabilidade (recreação de contato primário), avaliada nas categorias própria e imprópria, considerada a densidade de coliformes termotolerantes de um conjunto de amostras, em cada uma de cinco semanas anteriores e consecutivas.

As águas consideradas próprias poderão ser subdivididas nas seguintes categorias:

Tabela 3 - Classificação da qualidade das águas brasileiras.

\begin{tabular}{cl}
\hline Excelente: & $\begin{array}{l}\text { Quando em 80\% ou mais de um conjunto de amostras obtidas em } \\
\text { cada uma das cinco semanas anteriores, colhidas no mesmo local, } \\
\text { houver no máximo, } 250 \text { coliformes termotolerantes ou } 200 \\
\text { Escherichia coli ou } 25 \text { enterococos por } 100 \text { mililitros; }\end{array}$ \\
Quando em $80 \%$ ou mais de um conjunto de amostras obtidas em \\
cada uma das cinco semanas anteriores, colhidas no mesmo local, \\
houver, no máximo, 500 coliformes termotolerantes ou 400 \\
Escherichia coli ou 50 enterococos por 100 mililitros;
\end{tabular}

Fonte: adaptado de (BRASIL, 2000).

As águas serão consideradas impróprias, sendo desaconselhadas para recreação de contato primário, quando no trecho avaliado for verificada uma das seguintes ocorrências:

- $\quad$ Não atendimento aos critérios estabelecidos para as águas próprias;

- Valor obtido na última amostragem for superior a 2500 coliformes termotolerantes ou 2000 Escherichia coli ou 400 enterococos por 100 mililitros;

- Incidência elevada ou anormal, na região, de enfermidades transmissíveis por via hídrica, indicada pelas autoridades sanitárias;

- Presença de resíduos ou despejos, sólidos ou líquidos, inclusive esgotos sanitários, óleos, graxas e outras substâncias, capazes de oferecer riscos à saúde ou tornar desagradável a recreação;

- $\quad \mathrm{pH}<6,0$ ou $\mathrm{pH}>9,0$ (águas doces), à exceção das condições naturais;

- $\quad$ Floração de algas ou outros organismos, até que se comprove que não oferecem riscos à saúde humana; 
- $\quad$ Outros fatores que contraindiquem, temporária ou permanentemente, o exercício da recreação de contato primário.

\section{RESULTADOS E DISCUSSÕES}

Os resultados obtidos das amostras analisadas, assim como a média obtida nas cinco semanas do estudo para quantificação de Coliformes Termotolerantes nos corpos d'água dos cinco reservatórios da região Oeste são apresentados na (tabela 4) e dos quatro reservatórios da região do Seridó na tabela 5.

Segundo os dados obtidos durante o presente estudo, o Açude de Lucrécia apresentou valores de concentração de coliformes fecais/100 $\mathrm{mL}$ maiores que 1.000 , tornando-as impróprias para banho, segundo critérios da Resolução CONAMA 274/2000. A Barragem de Pau de Ferros apresentou valor de concentração de coliformes fecais/100 mL maior que 2.500 , portanto está imprópria para banho no período avaliado.

Tabela 4 - Valores de Coliformes Termotolerantes e médias (NMP/100 mL) determinados nos pontos amostrados nos mananciais da Região Oeste.

\begin{tabular}{|c|c|c|c|c|c|c|c|}
\hline $\begin{array}{c}\text { Reservatório } \\
\text { Hídrico }\end{array}$ & $\begin{array}{c}\text { Semana } \\
01 \\
10 / 03 / 13\end{array}$ & $\begin{array}{c}\text { Semana } \\
02 \\
17 / 03 / 13\end{array}$ & $\begin{array}{c}\text { Semana } \\
03 \\
24 / 03 / 13\end{array}$ & $\begin{array}{c}\text { Semana } \\
04 \\
31 / 04 / 13\end{array}$ & $\begin{array}{c}\text { Semana } \\
05 \\
07 / 04 / 13\end{array}$ & Média & $\begin{array}{c}\text { Classif. de } \\
\text { Balneabilidade } \\
\text { (Resolução } \\
\text { CONAMA no } \\
\text { 274/2000) }\end{array}$ \\
\hline $\begin{array}{c}\text { Açude } \\
\text { Bananeiras }\end{array}$ & 3 & 4 & 920 & 240 & 33 & 239 & PRÓPRIA \\
\hline $\begin{array}{c}\text { Barragem de } \\
\text { Pau dos } \\
\text { Ferros }\end{array}$ & 31 & 1600 & 79 & 79 & 2400 & 838 & IMPRÓPRIA \\
\hline $\begin{array}{c}\text { Barragem } \\
\text { Santa Cruz } \\
\text { do Apodi }\end{array}$ & 23 & 13 & 540 & 170 & 2600 & 669 & IMPRÓPRIA \\
\hline $\begin{array}{l}\text { Açude de } \\
\text { Lucrécia }\end{array}$ & 31 & 4 & 23 & 31 & 1600 & 338 & PRÓPRIA \\
\hline $\begin{array}{l}\text { Barragem } \\
\text { Armando } \\
\text { Ribeiro } \\
\text { Gonçalves }\end{array}$ & 240 & 13 & 23 & 110 & 920 & 261 & PRÓPRIA \\
\hline
\end{tabular}


Tabela 5 - Valores de Coliformes Termotolerantes e médias (NMP/100 mL) determinados nos pontos amostrados nos mananciais da Região Seridó.

\begin{tabular}{|c|c|c|c|c|c|c|c|}
\hline $\begin{array}{c}\text { Reservatório } \\
\text { Hídrico }\end{array}$ & $\begin{array}{c}\text { Semana } \\
01 \\
10 / 03 / 13\end{array}$ & $\begin{array}{c}\text { Semana } \\
02 \\
17 / 03 / 13\end{array}$ & $\begin{array}{c}\text { Semana } \\
03 \\
24 / 03 / 13\end{array}$ & $\begin{array}{c}\text { Semana } \\
04 \\
31 / 04 / 13\end{array}$ & $\begin{array}{c}\text { Semana } \\
05 \\
07 / 04 / 13\end{array}$ & Média & $\begin{array}{c}\text { Classif. de } \\
\text { Balneabilidade } \\
\text { (Resolução } \\
\text { CONAMA no } \\
\text { 274/2000) }\end{array}$ \\
\hline $\begin{array}{c}\text { Barragem de } \\
\text { Boqueirão }\end{array}$ & 12 & 33 & 46 & 23 & 5 & 24 & PRÓPRIA \\
\hline $\begin{array}{c}\text { Barragem de } \\
\text { Passagem de } \\
\text { Traíras }\end{array}$ & 33 & 240 & 12 & 23 & 13 & 64 & PRÓPRIA \\
\hline Açude Itans & 49 & 49 & 23 & 33 & 110 & 53 & PRÓPRIA \\
\hline $\begin{array}{c}\text { Açude de } \\
\text { Gargalheiras }\end{array}$ & 4 & 4 & 12 & 23 & 12 & 11 & PRÓPRIA \\
\hline
\end{tabular}

Os resultados obtidos das análises com vistas ao estudo para quantificação de densidade de Cianobactérias (cel/mL) nos corpos d'água, realizadas no dia 17/03/2013, são apresentados na tabela 8, para os cinco reservatórios da Região Oeste, e tabela 9, para os quatro reservatórios da Região do Seridó.

Como se pode observar na tabela 9, a barragem de Santa Cruz e o açude de Bananeiras ficaram abaixo do limite estabelecido pera resolução, os reservatórios Lucrécia e de Pau dos Ferros apresentaram valores de densidade de cianobactérias muito acima do limite da Resolução CONAMA no 357/2005, para mananciais da Classe 2 , que é de $50.000 \mathrm{cel} / \mathrm{mL}$.

Tabela 6 - Valores de Contagem de Cianobatérias (cel/100 mL) determinados nos pontos amostrados nos mananciais da Região Oeste.

\begin{tabular}{|c|c|c|c|c|c|c|}
\hline \multicolumn{7}{|c|}{ Contagem de Cianobactérias (Cel /mL) } \\
\hline Data & Lucrécia & $\begin{array}{l}\text { Eng. } \\
\text { Armando } \\
\text { Ribeiro } \\
\text { Gonçalves }\end{array}$ & Alexandria & $\begin{array}{c}\text { Santa } \\
\text { Cruz do } \\
\text { Apodi }\end{array}$ & $\begin{array}{c}\text { Pau dos } \\
\text { Ferros }\end{array}$ & $\begin{array}{c}\text { Limite } \\
\text { Classe } 2 \\
\text { (Resolução } \\
\text { CONAMA } \\
\text { no } \\
\text { 357/2005 } \\
\text { - Art. } 15\end{array}$ \\
\hline $17 / 03 / 13$ & 120.340 & 65.150 & 45.350 & 2.640 & 974.250 & 50.000 \\
\hline
\end{tabular}


Em relação aos mananciais da região do Seridó, obteve-se valores de cianobactérias muito acima do limite recomendado pela Resolução CONAMA no 357/2005 - para mananciais da Classe 2, para os reservatórios de Passagem das Traíras e Gargalheiras.

Tabela 7 - Valores de Contagem de Cianobatérias (cel/100 mL) determinados nos pontos amostrados nos mananciais da Região Seridó.

\begin{tabular}{|c|c|c|c|c|c|}
\hline \multicolumn{6}{|c|}{ Contagem de Cianobactérias (Cel /mL) } \\
\hline Data & $\begin{array}{c}\text { Passagem } \\
\text { Traíras }\end{array}$ & Gargalheiras & Boqueirão & Itans & $\begin{array}{c}\text { Limite } \\
\text { Classe } 2 \\
\text { (Resolução } \\
\text { CONAMA no } \\
\text { 357/2005 - } \\
\text { Art. } 15\end{array}$ \\
\hline $17 / 03 / 13$ & 320.834 & 236.402 & 23.450 & 4.530 & 50.000 \\
\hline
\end{tabular}

De acordo com a classe 2 para água doce, segundo resolução $n^{\circ} 357$ do CONAMA, os mananciais estão dentro dos padrões para os coliformes termotolerantes, com valores médio abaixo de $1000 \mathrm{NMP} / 100 \mathrm{~mL}$, e para os valores físico-químicos. Por outro lado, os reservatórios de Lucrécia, Pau dos Ferros, Armando Ribeiro, Passagem das Traíras e Gargalheiras as suas águas estão acima dos limites permitidos para as cianobactérias, que é de $50.000 \mathrm{cel} / \mathrm{mL}$.

Vieira e Oliveira (2001), estudando o grau de contaminação fecal da água da Lagoa de Parangaba, em Fortaleza-CE, encontraram valores para o NMP de coliformes termotolerantes inferiores aos encontrados nesta pesquisa, variando de 3,9.10 a 2,3.10 $/ 100 \mathrm{~mL}$

As florações de cianobactérias causam impactos sociais, econômicos e ambientais, principalmente pela produção de metabólitos secundários bioativos com altas propriedades tóxicas que podem afetar a saúde de muitos animais, inclusive do homem (YUNES, 1998; RIBEIRO, 2007).

Em relação aos metais pesados as médias dos resultados obtidos para o alumínio, cádmio, cobre, chumbo, cromo, manganês, níquel, prata e zinco das águas dos mananciais superficiais da Região Oeste encontram-se na tabela 8 , enquanto na tabela 9, tem-se os resultados dos mananciais superficiais da Região Seridó. Cabe ressaltar que em relação ao elemento Cadmio, esse metal é bioacumulativo e persistente no meio ambiente, onde a sua meia vida ( $\mathrm{t} 1 / 2$ ) é de 10 a 30 anos, além de representar um risco à saúde humana, podendo também provocar distúrbios gastrointestinais, após a ingestão do agente químico. Quando inalado produz intoxicação aguda, caracterizada por pneumonia e edema pulmonar. (USPHS, 1997; JÚNIOR 2008) 
Tabela 8 - Quantidade de metais pesados encontrados nas águas superficiais analisadas da Região Oeste.

\begin{tabular}{c|c|c|c|c|c|c}
\hline $\begin{array}{c}\text { Parâmetro } \\
\text { (mg/L) }\end{array}$ & Bananeiras & Lucrécia & $\begin{array}{c}\text { Pau dos } \\
\text { Ferros }\end{array}$ & $\begin{array}{c}\text { Santa } \\
\text { Cruz }\end{array}$ & ARG* & $\begin{array}{c}\text { Limite } \\
\text { classe 2 } \\
\text { CONAMA } \\
\text { Resolução } \\
\mathbf{3 5 7 / 0 5}\end{array}$ \\
\hline Alumínio & 0,440 & 0,199 & 0,220 & 0,033 & 0,382 & 0,100 \\
Cádmio & 0,006 & 0,003 & 0,006 & 0,006 & 0,004 & 0,001 \\
Cobre & 0,005 & 0,003 & 0,004 & 0,001 & 0,014 & 0,009 \\
Chumbo & 0,000 & 0,000 & 0,000 & 0,000 & 0,000 & 0,010 \\
Cromo & 0,000 & 0,001 & 0,000 & 0,000 & 0,000 & 0,050 \\
Manganês & 0,106 & 0,022 & 0,130 & 0,514 & 0,040 & 0,100 \\
Níquel & 0,030 & 0,000 & 0,020 & 0,000 & 0,000 & 0,025 \\
Prata & 0,000 & 0,000 & 0,000 & 0,000 & 0,000 & 0,010 \\
Zinco & 0,000 & 0,000 & 0,000 & 0,000 & 0,000 & 0,180 \\
\hline
\end{tabular}

Tabela 9 - Quantidade de metais pesados encontrados nas águas superficiais analisadas da Região Seridó

\begin{tabular}{c|c|c|c|c|c}
\hline $\begin{array}{c}\text { Parâmetro } \\
\text { (mg/L) }\end{array}$ & Itans & Traíras & Boqueirão & Gargalheiras & $\begin{array}{c}\text { Limite } \\
\text { classe 2 } \\
\text { CONAMA } \\
\text { Resolução } \\
\mathbf{3 5 7 / 0 5}\end{array}$ \\
\hline Alumínio & 0,105 & 0,472 & 0,131 & 0,086 & 0,100 \\
Cádmio & 0,005 & 0,006 & 0,007 & 0,005 & 0,001 \\
Cobre & 0,007 & 0,012 & 0,014 & 0,010 & 0,009 \\
Chumbo & 0,000 & 0,000 & 0,000 & 0,000 & 0,010 \\
Cromo & 0,000 & 0,000 & 0,000 & 0,000 & 0,050 \\
Manganês & 0,033 & 0,089 & 0,025 & 0,104 & 0,100 \\
Níquel & 0,010 & 0,010 & 0,020 & 0,020 & 0,025 \\
Prata & 0,000 & 0,000 & 0,000 & 0,000 & 0,010 \\
Zinco & 0,000 & 0,000 & 0,000 & 0,000 & 0,180 \\
\hline
\end{tabular}

Quanto à concentração de Alumínio Total, pode-se constar que todos os mananciais estudados apresentaram concentrações médias acima do limite recomendado pela Resolução CONAMA no 357/2005 para mananciais da Classe 2 (caso destes citados), que é Al = 0,1 mg/L com exceção dos reservatórios de Santa Cruz e Gargalheiras que apresentou média de concentração de alumínio dentro do limite recomendado pela Legislação.

Em relação ao Cádmio Total, pode-se constar que todos os mananciais apresentaram concentrações médias acima do limite recomendado pela Resolução CONAMA acima referida, que para mananciais da Classe 2 (caso destes citados) é $\mathrm{Cd}=0,001 \mathrm{mg} / \mathrm{L}$.

Em relação ao Cobre Total, constatou-se que os reservatórios de Armando Ribeiro Gonçalves, Passagem das Traíras, boqueirão e Gargalheiras apresentaram concentração média 
pouco acima do limite recomendado pela Resolução CONAMA no 357/2005 para mananciais Classe 2 (caso destes citados), que é $\mathrm{Cu}=0,009 \mathrm{mg} / \mathrm{L}$.

Em relação ao Chumbo, Cromo, níquel, prata e zinco, constatou-se que nenhum manancial estudado apresentou concentração média acima do limite recomendado pela Resolução CONAMA no 357/2005 para mananciais Classe 2 (caso destes citados), que é $\mathrm{Pb}=0,01 \mathrm{mg} / \mathrm{L}, \mathrm{Cr}=0,05 \mathrm{mg} / \mathrm{L}$, $\mathrm{Ni}=0,025 \mathrm{mg} / \mathrm{L}, \mathrm{Ag}=0,050 \mathrm{mg} / \mathrm{L}$ e $\mathrm{Zn}=0,18 \mathrm{mg} / \mathrm{L}$.

Os reservatórios de Bananeiras, Pau dos Ferros, Santa Cruz e Gargalheiras estudados apresentaram concentrações médias de Manganês total acima do limite recomendado pela Resolução CONAMA no 357/2005 para mananciais Classe 2 (caso destes citados), que é Mn = 0,1 $\mathrm{mg} / \mathrm{L}$. Enquanto a Barragem de Boqueirão, Barragem Armando Ribeiro, Barragem Passagem das Traíras, Açude de Lucrécia e Açude Itans se mostraram abaixo do limite permissível.

O metal manganês, nos reservatórios: Bananeiras, Pau dos Ferros, Santa Cruz e Gargalheiras apresentaram-se com concentração acima do limite permitido. De acordo com Candurra (2000), o manganês em concentrações superiores as máximas permitidas, são considerados neorotóxicos, capazes de induzir funções neurais ou causar lesões no sistema nervoso central ou periférico.

Os reservatórios de Armando Ribeiro, Boqueirão, Passagem das Traíras e Gargalheiras encontra-se acima do limite. O Al é um dos mais freqüentes causadores de intoxicações por metais pesados, pode alterar as estruturas celulares, as enzimas e ainda substituir metais co-fatores de atividades enzimáticas, forma radicais livres e por efeito cumulativo leva a processos degenerativos; têm sido encontrado um índice elevado desse metal em pacientes portadores do Mal de Alzheimer (Pascalicchio, 2002).

\section{CONCLUSÕES}

Os reservatórios hídricos: Barragem de Santa Cruz do Apodi, Barragem Armando Ribeiro, Barragem Passagem das Traíras, Açude Bananeiras, Açude Gargalheiras, Barragem de Boqueirão e Açude Itans apresentaram-se com águas próprias para banho, segundo critérios estabelecidos pela Resolução CONAMA 274/2000, com valores de coliformes termotolerantes inferiores a 1.000 $\mathrm{NMP} / 100 \mathrm{~mL}$ em todas as cinco etapas de amostragens. Enquanto os reservatórios: Açude de Lucrécia e Pau dos Ferros apresentaram-se com águas impróprias para banho, segundo a mesma Resolução.

Quanto à qualidade biológica os mananciais: Açude Lucrécia, Barragem de Pau dos Ferros, Açude de Gargalheira, Barragem Passagem das traíras e Barragem Armando Ribeiro, apresentaram densidade de cianobactérias acima do limite da Resolução CONAMA 357/2005 para rios classe 2 $(50.000 \mathrm{cel} / \mathrm{mL})$, sendo indicativo do fenômeno de eutrofização. Esses dados caracterizam um problema grave e muito preocupante, uma vez que esses mananciais são responsáveis pelo abastecimento de água na região do Alto Oeste, Seridó e Mossoró. Os demais mananciais apresentaram-se dentro da normalidade. 
A qualidade das águas dos mananciais para fins de dessedentação animal está prejudicada pela elevada quantidade de cianobactérias.

Nos mananciais estudados, quanto aos metais pesados, todos apresentaram valores dentro dos limites da Resolução para os metais: alumínio, chumbo, cromo, níquel, prata e zinco. Em relação ao metal cádmio, em todos os reservatórios estudados, esse metal apresentou-se com concentração acima do permitido pela Legislação, com exceção da Barragem Armando Ribeiro.

\section{REFERÊNCIAS BIBLIOGRÁFICAS}

APHA - AMERICAN PUBLIC HEALTH ASSOCIATION. Standard Methods for the Examination of Water and Wastewater. New York: 21aㅡ ed., 1134 p., 2005.

BARBOSA, J. E. L. Dinâmica do fitoplancton e condicionantes limnológicos nas escalas de tempo (nictimeral/sazonal) e de espaço (vertical/horizontal) no açude Taperoá II. Trópico semi-árido paraibano. 2002, 208f. Tese (Doutorado em Recursos Naturais) - Departamento de Ecologia e Recursos Naturais - Universidade Federal de São Carlos, São Carlos - SP

BRASIL. Brasília-DF (Brasil). Conselho Nacional do Meio Ambiente (CONAMA) - Resolução CONAMA N ${ }^{0}$ 274, de 29 de novembro de 2000. Ministério do Meio Ambiente (MMA) 2000. Define os critérios de balneabilidade em águas brasileiras.

BRASIL. Ministério do Meio Ambiente (MMA). Conselho Nacional do Meio Ambiente (CONAMA). Resolução CONAMA № 357, de 17 de março de 2005. Dispõe sobre a classificação dos corpos de água e diretrizes ambientais para o seu enquadramento, bem como estabelece as condições e padrões de lançamento de efluentes, e dá outras providências, 2005.

CANDURRA, S.M; BUTERA, R.; GANDINI, C; LOCATELLI, C.; TAGLIANE, M; FASOLA, D.; MANZO, L. Occuptaional poisoning with psychiatric manifestations . Giornale Italiano di medicina del Lavoro ed Ergonomia, Pavia, v.22, n.1, p 52-61, 2000.

CETESB (COMPANHIA DE TECNOLOGIA DE SANEAMENTO AMBIENTAL). Coleta e Preservação de Amostras de Água. São Paulo: Governo do Estado de São Paulo. Secretaria do Meio Ambiente, 53 p. 2003.

CETESB (COMPANHIA DE TECNOLOGIA DE SANEAMENTO AMBIENTAL). Estudo de desenvolvimento e adaptação de IQA - índice de qualidade das águas que incorpora nove variáveis relevantes ao IQA da National Sanitation Foundation (1970). Secretaria do Meio Ambiente, 123 p. 1980.

CETESB. (COMPANHIA DE TECNOLOGIA DE SANEAMENTO AMBIENTAL). Índice de Qualidade das Águas (IQA). Disponível em http://www.cetesb.sp.gov.br. Acesso em 20/10/2013.

GASPARINI, V. A. (2001) - Repercussões econômicas da utilização incorreta das áreas de mananciais. UFSC. Engenharia de Produção. Dissertação de Mestrado.

JÚNIOR, A. M. Cádmio - Intoxicação. Medicina geriátrica (Revista eletrônica). Publicado em 24/03/2008. Disponível em: http://www.medicinageriatrica.com.br (acesso em 20/02/2009). 
LIMA, W.S.; GARCIA, C.A.B. Qualidade da Água em Ribeirópolis-SE: o Açude do Cajueiro e a Barragem do João Ferreira. Scientia Plena, v.4, n.12, 2008.

PASCALICCHIO A.E, Contaminação por metais pesados. São Paulo: Associação de Profissionais em Ciência Ambiental; 2002. p.31, 40-41.

RIBEIRO, P.C. Análise de fatores que influenciam a proliferação de cianobactérias e algas em lagoas de estabilização. Campina Grande, 2007. 106 pp. Dissertação ( Engenharia Civil). Centro de Tecnologia e Recursos Naturais. Universidade Federal de Campina Grande.

RIBEIRO, I. V. A. S. Estudo do Estado Trófico do Reservatório Acarape do Meio Mediante a Determinação de Indicadores de Qualidade de Água. Tese de doutorado em Recursos Hídricos. Departamento de Engenharia Hidráulica e Ambiental - Universidade Federal do Ceará, Fortaleza, 198p., 2007.

Silva, d. D.; Pruski, f. F. (2000). Gestão de recursos hidrícos. Aspectos legais, econômicos, administrativos e sociais. Porto alegre: associação brasileira de recursos hídricos. 659p.

U.S. PUBLIC HEALTH SERVICES - USPHS (1997). Toxicological profile for cadmium on CD-ROM. Agency for Toxic Substances and Disease Registry.

VIEIRA, R.H.S.F.; OLIVEIRA, R.A. Avaliação do grau de contaminação fecal da água e do camarão sossego (Macrobrachium jelskii). Hig. Alim., v.15, p.69- 74, 2001. 